\title{
TRÂNSITOS BINÁRIOS NA CENA ALMODOVARIANA: UM ESTUDO SOBRE FALE COM ELA
}

\author{
BINARY TRANSITS IN THE ALMODOVAR'S SCENE: \\ A STUDY ABOUT TALK TOHER
}
TRANSIT BINAIRE DANS LA SCENE ALMODOVARIENNE: UNE ÉTUDE SUR PARLE AVEC ELLE

Danilo Pereira SANTOS; Caio César Silva ROCHA.

RESUMO:

O binarismo ou sistema binário é um construto histórico / social / discursivo que agrega dispositivos normativos de circunscrição dos comportamentos, das ações, das disposições psicoemocionais dos individuos, polarizando, regulando e localizando os corpos em duas categorias de gênero aparentemente imutáveis, estáveis e coerentes o masculino e o feminino ditando como homens e mulheres devem se portar de acordo a suas marcas corporais (pênis e vagina). Partindo desse pressuposto, este trabalho tem por objetivo a análise do longametragem Fale com Ela, do diretor espanhol Pedro Almodóvar, em que questões sobre binarismo sexual são evidenciadas, desconstruidas e problematizadas com base nas cirandas de amor e morte que envolvem os / as personagens centrais do filme.

PALAVRAS-CHAVE:

Cinema Almodovariano;

Binarismo sexual; Sexualidades.
ABSTRACT:

Binarism or binary system is a historical/social / discursive construct that aggregates normative devices for circumscribing individuals' behaviors, actions, psychoemotional dispositions, polarizing, regulating and locating bodies in two apparently immutable, stable and coherent gender categories - male and female - dictating how men and women should behave according to their body marks (penis and vagina). Based on this assumption, this paper aims to analyze longterm analyzes Talk To Her, by the Spanish director Pedro Almodóvar, on issues related to sexual binary are highlighted, deconstructed and problematic based on circles of love and death that surround the central characters of the movie.

\section{KEYWORDS:}

Almodóvar's cinema;

Gender binarism; Sexualities.
RÉSUMÉ:

Le binarisme ou système binaire est une construction historique / sociale / discursive qui regroupe des dispositifs normatifs pour circonscrire les comportements, les actions et les dispositions psycho-affectives des individus, polarisant, régulant et localisant les corps dans deux catégories de genre apparemment immuables, stables et cohérentes - hommes et femmes - dictant aux hommes et aux femmes comment se comporter en fonction des marques de leur corps (pénis et vagin). Sur la base de cette hypothèse, ce travail vise à analyser le long métrage Parle Avec Elle, du réalisateur espagnol Pedro Almodóvar, dans lequel les problèmes liés au binaire sexuel sont mis en évidence, déconstruits et problématisés à partir des groupes d'amour et de death qui les entourent. personnages centraux du film.

MOTS-CLÉS:

Cinéma Almodovarien;

Binaire sexuel; Les sexualités. 
UM PASSEIO POR PARTE DA FILMOGRAFIA DE PEDRO

ALMODÓVAR:

\section{CONSIDERAÇÕES INICIAIS}

Consideramos oportuno iniciar este artigo afirmando que os filmes do diretor espanhol Pedro Almodóvar possuem algo em comum: desafiam o padrão da sexualidade dominante ao explorar as subjetividades e as corporalidades que fogem à estabilidade dos gêneros (GALLINA, 2010). Além disso, a filmografia do cineasta é

\section{[...] é repleta de questões de gênero e sexualidade. Personagens transexuais, travestis, homossexuais, lésbicas, prostitutas, relacões \\ transgressoras, opressoras, perversões sexuais e mulheres à beira de um ataque de nervos são partes de sua obra [...] (GALLINA, 2010, p. 76).}

Os primeiros filmes de Almodóvar foram lançados na década de 1980. Estes e todos os outros que se seguiram têm grande influência do destape, movimento que surge na Espanha pós-franquista. Esse movimento, de acordo com Justina Franchi Gallina (2008) possibilitou diversos diretores a realizarem filmes de cunho político (com pitadas de erotismo), que evidenciam questões sobre gênero e diversidade sexual, por exemplo, principalmente com o intuito de criticar, questionar e desvelar o que por muitos anos foi proibido nas telas devido à censura imposta pelo governo ditatorial de Francisco Franco. Exemplo disso é De Salto Alto (Tacones Lejanos, 1991), longa que narra a história de mulheres independentes, sexualmente resolvidas e uma drag queen, características das representações de feminilidades pós-modernas ou feminilidades contemporâneas. Provocativo, o diretor desestabiliza o conceito de maternidade imposta pela tradição judaico-cristã ao contar a história de Becky (Marisa Paredes), famosa atriz e cantora que abandona sua filha para se dedicar à vida profissional.

Ainda nessa obra, ao narrar o drama de Letal (Miguel Bosé) Almodóvar pratica atravessia de gênero (LOURO, 2008): Durante o dia, ele é Juez Dominguéz, delegado da cidade. Nas noites madrileñas, a personagem se traveste e adota o pseudônimo de Letal para se apresentar como drag queen numa boate voltada ao público gay. Assim, diante das características apontadas da persona Dominguéz representa um ser entre fronteiras, pois transita entre as instâncias binárias masculino/feminino.

É válido ressaltar também, que a vasta filmografia almodovariana contribui para a desconstrução dos discursos e ideologias heteronormativas dos sexos / gêneros (SILVA ROCHA E PEREIRA SANTOS, 2014), desagregando os papéis atribuídos a cada um dos constituintes do eixo binário masculino/feminino (GALLINA, 2008). Duas películas melhor exemplificam essa assertiva, são elas: A Pele que Habito (Piel que habito, la, 2011) e A Lei do Desejo (Ley del deseo, la, 1987). Nesta, uma das personagens centrais é a transexual Tina (Carmem Maura). Ainda menino, a personagem de Maura mantém um relacionamento incestuoso com o pai, que financia a intervenção cirúrgica de mudança de sexo daquela.
Porém, quando ele a abandona, Tina passa a odiar todos os homens. Para Gallina (2008), essa persona desafia o padrão de sexualidade dominante, pois não ocupa um lugar ou outro, mas vive entre fronteiras.

Em A Pele que Habito, Almodóvar opõe, anula, redefine e confunde o universo masculino e feminino. Numa noite festiva, Vicente (Jan Cornet) estupra a filha do cirurgião plástico Robert (Antonio Banderas). O cirurgião jura se vingar daquele e o sequestra. Parte do plano é fazer uma cirurgia de mudança de sexo no rapaz. Agora Vicente se "transforma" em Vera Cruz (Elena Anaya) e se torna prisioneira de Robert. A personagem Vicente/Vera Cruz proporciona um debate sobre a transexualidade,

incompatibilidade entre sexo anatômico e identidade,

como um desencaixe entre a interioridade do sujeito e a exterioridade do seu corpo (RODRIGUES E HEILBORN, 2014).

A filmografia almodovariana é palco de polêmicas leituras e releituras das vivências, dos sentidos de existência, da transgressão dos comportamentos socialmente desejáveis e impostos a homens e mulheres. Importa observar como esses códigos de conduta são transgredidos - e até mesmo subvertidos - pelo diretor e quais efeitos podem produzir. Em Fale com Ela, objeto de análise desse texto, questiona-se como o binarismo sexual é problematizado na obra; antes, porém, um olhar sobre os dramas de amor e morte fornecerá aspectos fundamentais para compreender a extensão da discussão sobre o binarismo. 
CIRANDAS DE AMOR E DE MORTE

Um olhar atento sobre Fale com Ela não deixaria passar despercebidos aspectos tão relevantes e imprevisíveis quanto $\mathrm{O}$ amor e a morte. São elementos significativos e que auxiliam na compreensão das histórias urdidas e no modus operandi de cada persona almodovariana. Essas inflexões são responsáveis, por exemplo, pela instabilidade das relações, que nunca duram mais que 0 necessário, conotando por diversas vezes uma espécie de permuta entre sentimentos e desejos.

Há no amor certa temeridade compartilhada pela morte (BAUMAN, 2004). Cabe indagar, contudo, em que medida 0 sofrimento proveniente dessas travessias pode constituir-se numa aprendizagem. Mas, o que o amor e a morte têm em comum? Partilham, sobretudo, o caráter individual da experimentação, ou seja, suas representações racionais pelos seus conteúdos pouco valem (ou de nada valem) se não puderem ser sentidos, sofridos na pele. Ainda que se possa teorizar sobre esses ritos, somente a imediata e efetiva vivência pode dar-lhe uma representação significativa para aquele que a vivencia (VIESENTEINER, 2014). Essa vivência, por assim dizer, emocional ou experiência intencional (AMATUZZI, 2007), é o que se designa na filosofia como Erlebnis, que pode ser compreendido como presenciar em vida um evento no momento de sua ocorrência.

Café Muller (1978), espetáculo de Dança-Teatro da artista Pina Bausch, conduz a plateia, na cena inicial de Fale com Ela, ao drama do sofrimento, ao tempo em que antecipa o que se constituirá na ambivalência de destinos complexos, incertos e divergentes. Duas mulheres, de olhos cerrados, ocupam um palco cheio de cadeiras e mesas. À medida que se deslocam, concomitantemente,

em direções imprevisíveis, perturba o expectador à possibilidade de que esbarrem nos objetos espalhados pelo cenário impedido o choque pela presença de um homem com semblante pesaroso, encarregado de abrir caminho para que a encenação aconteça.

No rosto das bailarinas há profunda expressão de angústia e emerge da plasticidade de seus gestos e ações a letargia em que estão envoltos os corpos que se movimentam. Na plateia, dois homens, desconhecidos entre si, atentos ao balé, o jornalista Marco (Dario Grandinette), que chora convulsivamente durante a execução do espetáculo, e o enfermeiro Benigno (Javier Cámara) que percebe a emoção do companheiro de assento.

Um corte. O telespectador é transportado a um quarto de hospital, e sobre a cama, nua, a bailarina Alicia (Leonor Watling), em coma, e Benigno, a cuidar-lhe do corpo. Este the conta o que vira durante a apresentação de Bausch. Aliás, desde que acometida pelo coma, Alicia terá seus hábitos e hobbies adotados pelo enfermeiro, seu admirador desde antes do incidente. Peças de balé, filmes, o cotidiano da bailarina é incorporado por Benício. Mas, por quê?

A assertiva não é tão simples, pois os impulsos vitais que o propelem a assumir um estilo de vida que não the pertence termina por engendrar a busca da própria satisfação, tendo em
Alicia o objeto de pulsão. Mesmo não podendo emitir palavra alguma, a existência da bailarina é vital para satisfazer Benigno. Por isso, enquanto travessia/vivência o modo de agir do enfermeiro é pathetica, pois se torna uma construção individual difícil de assimilar, que causa estranheza - para ele, "falar" com Alicia sobre tudo o que ela gostava de fazer antes do incidente é tão natural como os cuidados dispensados ao corpo - em contraponto a Marco, vivenciando condição parecida com a toureira Lydia (Rosario Flores), não conseguir sequer romper o silêncio.

Benigno não pode viver sem Alicia. Eros também não suporta a existência de uma vida sem Psiquê. É a vontade de cuidar, de preservar o objeto do zelo (BAUMAN, 2004), de estar sempre perto que desencadeará o sentimento de amor? Bauman reconhece que "[...] Eros é possuído pelo fantasma de Tanatos, que nenhum encantamento mágico é capaz de exorcizar. A questão não é a precocidade de Eros, e não há instrução ou expedientes autodidáticos que possam libertá-lo de sua mórbida suicida - inclinação." (2004, p. 22). Logo, Eros, que é capaz das mais belas demonstrações de afeto, pode tornar-se ao mesmo tempo obsessivo, esmagador, implacável.

Em contraste, Lydia, advinda de uma relação conturbada com Niño de Valencia (Adolfo Fernández), colega de profissão - toureiro, atada a um compromisso recente com Marco. A aproximação desse par ocorre num flerte de bar: o jornalista procura ocasião para entrevistar a toureira sobre sua vida pessoal e obter uma boa matéria, ela, por outro lado, parece não suportar o fato de 
ter sido abandonada pelo seu parceiro anterior. A solidão Ihe é detestável.

Três fatores relevantes se impõem: 1 - Lydia não ama Marco, apenas inclina-se carinhosamente a ele. Seu coração pertence a Niño de Valencia. 2 - Marco é atormentado pelo fantasma de um antigo amor, Ângela, e, por mais que se esforce, não pode evitar esquecê-lo, embora afirme o contrário; 3 - Durante a viagem a Lucena, ambos travam um interessante diálogo sobre o passado amoroso do jornalista. A certa altura da conversa, Lydia pergunta se ele ainda a amava. A resposta é, no mínimo, reveladora: "- Sim. Por isso chorava quando via algo que me emocionava. Porque não podia dividir isso com ela. Não há nada pior do que abandonar alguém que se ama". E mais adiante conclui: "O amor é a coisa mais triste do mundo quando acaba... como diz uma canção de Jobim" (ALMODÓVAR, 2002).

O abandono de alguém que se ama origina o mal-estar do vazio interior. Para compensar ou preencher as lacunas existentes, a busca da felicidade pela satisfação do prazer é que conduz o indivíduo na busca por outros relacionamentos, na emergência de "[...] mitigar a insegurança que infestou sua solidão; mas o tratamento só fez expandir os sintomas, e agora talvez você se sinta mais inseguro do que antes, ainda que essa "nova e agravada" insegurança provenha de outras paragens." (BAUMAN, 2004, p. 30). É o que deixa supor a relação de Lydia e Marco.

Na ocasião de uma cerimônia de casamento é quando a insegurança do compromisso de Lydia com Marco tornar-se explícita. Ela chora e é questionada pelo jornalista quanto à demonstração da emoção. Nada responde. Protela uma conversa para depois da tourada que não chega a acontecer: ferida pelo touro, entra em coma irreversível. É quando, numa visita, encontra Niño noquarto de Lydia segurando sua mão e conversando com esta, que Marco afinal é informado do reatamento ocorrido um mês antes do incidente.

Como mencionado no início dessa seção, Almodóvar propositalmente arrefece os laços de amor dos potenciais pares na trama. Essa dinâmica é necessária para a instalação de conflitos que desestabilizam a noção de relacionamento duradouro e aponta para a transitoriedade das ligações amorosas. Algumas destas, deveras, sequer se movem no sentido da realidade: estão condenadas a duração de uma centelha, obliteradas pela rápida consumação do desejo, que desde o seu nascimento está impregnado pela vontade de morrer (BAUMAN, 2004).

Os descompassos do amor em Fale com Ela são semelhantes ao que Drummond expressa em Quadrilha. São grandes redes de subordinação e ocultação em que os afetos estão à disposição, em sua maioria, das necessidades prementes dos seres humanos. Observa Aparecida Mendes Barbalho (2009, p. 3), sobre o poema, que nos movimentos sugeridos pelo próprio ritmo da dança que o intitula "[...] Explicita-se uma visão de rotação, sugere movimento ao mesmo tempo de renúncia, é um plano de sucessivos deslocamentos, de sentimentos, de conceitos, de posições e contradições."

Assim como em Drummond, a predominância dos diversos fatores circunscritos no sofrimento que interferem nas vivências das personagens da película termina por limitar suas paixões amorosas. Porém, a "[...] presença de caráter dramático da descontinuidade, a inversão das posições de sujeitos que resulta na alternância sentimental" (id.) é que possibilitará a variação de predominância de um indivíduo para outro.

Deste modo, temos o amor que Benigno nutre por Alicia. Esta, por sua vez, sempre mexeu com o coração de sua professora de balé, Katerina Bilova (Geraldine Chaplin). Marco amava Ângela, mas foi abandonado pela mesma. Desiludido com o amor, ele conhece Lydia e apaixona-se por ela. Lydia fora casada com Niño de Valencia, mas acabaram se separando. Rosa (Mariola Fuentes), enfermeira da clínica que Benigno trabalha, é apaixonada por ele, mas este nada percebe. Há também o amor entre Marco e Benigno, fio condutor da trama, e que em meio a duas mortes será a porta de entrada para uma nova história de amor, dessa vez entre Marco e Alicia. Aqui cabe, ainda, uma última observação.

Amante Minguante (Amante Menguante), curta do cinema mudo feito para ser exibido dentro do longa Fale com Ela, sinaliza o momento em que o sentimento do amor rivaliza com o ardor do desejo. É finalmente agui que o embate entre o ego e o superego se intensifica, entre a necessidade de satisfação pessoal através do objeto da pulsão, mesmo que parcialmente (LAGO, 2009), e a submissão ao aparato de valores e normas convencionais da sociedade ou grupo social ao qual o indivíduo pertence (id., ibid.) 
A metalinguagem utilizada por Almodóvar é duplamente significativa: provoca a abertura para a discussão binária dos gêneros, que será aprofundada na seção posterior, bem como conota a perversão de Benigno ao cometer o estupro contra Alicia. Aliás, pelos olhos do enfermeiro é que o público toma conhecimento do ocorrido, enquanto narra Amante Minguante para a paciente indefesa. É uma espécie de autoflagelação imposta à personagem que pela confissão admite seu crime.

Benigno é penalizado no corpo e na alma. Encontra o alívio para ambos no suicídio. Eros sucumbe ferido perante Tanatos. Mas como inferido em Drummond, as danças de amor e morte costumam encerrar um clico sem, todavia, extingui-lo totalmente.

Assim, é na alternância dos passos, na troca dos pares, que novas possibilidades amorosas são aventadas. Marco e Alicia trocam olhares emblemáticos durante o espetáculo de Pina Bausch, Masurca Fogo (1998). A leitura apreendida dessa cena aponta para o recomeço das cirandas de amor e morte, pois, conforme Bauman (2004),

[...] não se pode aprender a amar, tal como não se pode aprender a morrer. E não se pode aprender a arte ilusória inexistente, embora ardentemente

desejada - de evitar suas garras e ficar fora de seu caminho. Chegando

0

momento, o amor e a morte atacarão - mas não se tem a mínima ideia de quando isso acontecerá. Quando acontecer, vai pegar você desprevenido. Em nossas preocupações diárias, - amor e a morte aparecerão ab nihilo a partir do nada (p. 1718).

Eros, enfim, resiste à própria sorte e abraça o seu destino.

\section{A LÓGICA BINÁRIA DOS SEXOS}

As narrativas mais antigas convergem curiosos aspectos sobre a construção da diferença material dos sexos, estabelecendo relações de complementaridade e oposição. Platão alude em $O$ banquete (1991) que a natureza anterior da raça humana diferia da conhecida de hoje. Havia três gêneros humanos: o masculino, o feminino e o andrógino. Este compartilhava características comuns daqueles, do qual, refere-se o filósofo, "[...] resta agora um nome, desaparecida a coisa." (PLATÃo, 1991, p. 58).

A narrativa nos conduz ao arremate deste "gênero distinto". Por causa de sua grande força e presunção, ao tentar invadir o Olimpo, recebem de Zeus, como castigo, a separação dos corpos masculino e feminino são desmembrados. Seus rostos eram repuxados, por Apolo, em direção à parte amputada para que lembrassem o que foram um dia, como sinal de moderação.

E como sentissem saudade da parte de que foram separados, buscavam desesperadamente unir-se novamente a ela, morrendo de fome e desespero por não conseguirem fazer nada longe um do outro. Quando uma das metades morria, a que ficara viva procurava por uma outra, fosse homem ou mulher. E assim começaram a se exterminar. Zeus,observando o curso dos acontecimentos, decide mudar-Ihes o sexo para frente - antes era para fora, restringindo-os a copularem e gerarem somente com a terrapermitindo-Ihes agora processar a geração um no outro, o homem na mulher.

\section{Partindo da narrativa}

acima, a questão que se impõe primeiramente é: os caracteres movidos para a apreensão e instauração das diferenças materiais dos corpos são de que ordem (ou de quais ordens)? E uma segunda: essas diferenças primeiras desencadeiam quais outras? $\bigcirc$ espaço disponível para apreciação de tais indagações restringe as considerações a aspectos sucintos, reconhecida a complexidade de ambas.

Binarismo ou sistema binário é um construto histórico / social / discursivo que agrega dispositivos normativos de circunscrição dos comportamentos, das ações, das disposições psicoemocionais dos indivíduos, polarizando, regulando e localizando os corpos em duas categorias de gênero aparentemente imutáveis, estáveis e coerentes, masculino ou feminino. Nessa lógica, o indivíduo conserva um status quo que garante a permanência e regulação dos valores consentâneos de cada sexo. Mas, quais valores são esses? E, efetivamente, eles são percebidos e exercidos igualmente por todos os homens e mulheres?

É complicado apontar a gênese da problemática dos gêneros, embora se saiba que suas ramificações influenciem o modo de organização social 
e política de espaços públicos e privados. Nessa perspectiva, Joan Scott (1995) forja umconceito de gênero dividindo-o em duas partes e várias subpartes, interdependentes, a saber:

[...] o gênero é um elemento constitutivo de relacões sociais baseado nas diferencas percebidas entre os sexos, e o gênero é uma forma primeira de significar as relacões de poder (p. 86).

Na esteira do pensamento de Scott (1995), o gênero como subpartes cita os símbolos culturalmente disponíveis, os conceitos normativos de interpretação do sentido dos símbolos, a explosão da noção de fixidez dos gêneros no político, nas instituições e organizações sociais e, por fim, a identidade de gênero.

Nota-se, todavia, que as categorias binárias de gênero assumem função paradoxal: ao estabelecer as fronteiras entre os sexos, sustentando a noção de lugar dos sujeitos, motiva a existência de certa tranquilidade quanto à conduta afirmativa dos papéis sociais humanos ("homem é homem, mulher é mulher!"); em contrapartida, o processo de materialização do sexo nos corpos, imposta por "práticas altamente reguladas", nunca acontece plenamente, ou seja, a reprodução dessas normas regulatórias nunca é idêntica. São as possibilidades abertas por essa rematerialização, dispersas em novas figuras, que propiciarão novas e divergentes articulações não previstas pela/na lei regulatória (BUTLER, 2000).

Butler (2000) adverte que as práticas discursivas não somente marcam as diferenças sexuais, esses efeitos distintivos são causados também pelo próprio discurso. Observe, por exemplo,que uma vez distinguido o sexo biológico de um feto (ele ou ela), ainda na sala de ultrassonografia estabelece-se pari passu toda uma expectativa em torno desse novo ser social, desde o nome que receberá até com quem poderá se relacionar, estando todos esses efeitos submetidos, nesse instante, aos discursos médico e familiar, que antecipam, em certo grau, a reiteração autorizada desse domínio discursivo, em outras instâncias, ao longo da vida do indivíduo. É o "efeito naturalizado" do gênero a que se refere à filósofa.

Os parâmetros das generalizações devem ser questionados exatamente pela aparente naturalidade que tentam impor. Quando os discursos autorizados $e$ hegemônicos valem-se da distinção anatômica dos sexos para justificar as desigualdades entre homens e mulheres, estão produzindo 0 efeito naturalizado do gênero, enquanto a compreensão é de que essas diferenças são socialmente constituídas.

É necessário verificar ainda que se os discursos alimentam provocam e reiteram as distinções de gênero, o fará sempre por mecanismos de exclusão (SILVA ROCHA \& ROCHA JR., 2019). Significa dizer que a busca é, afinal sempre do humanamente inteligível. O problema dessa matriz é que tudo o que não cabe dentro das linhas, das fronteiras, dos limites impostos, que não está apropriadamente generificado, tem a sua própria humanidade tornada incerta.
Não caber nos campos semânticos e morfológicos de um dado gênero, desequilibrar as "[...] fronteiras com a persistente possibilidade de sua perturbação e rearticulação" (BUTLER, 2000, p. 117), originou o conceito de abjeção, daquilo que causa repulsa. O lugar da abjeção é ocupado pelos corpos que não se conformam e que preferem transitar, que "[...] não se contentam apenas em mudar de um "lugar" para outro e escolhem viver na fronteira, numa espécie de entre-lugar." (LOURO, 2008, p. 87, grifo da autora).

Embora os discursos / narrativas dominantes sejam maioria, historicamente mais antigos e insistam em demonstrar através de efeitos de naturalização as singularidades dos gêneros, outros discursos/narrativas recentes passaram a questionar essas "verdades", disseminando outra visão do processo de materialização dos sexos e construção dos gêneros, como é - caso da linguagem cinematográfica, personificada aqui por Almodóvar em seu filme objeto de análise, Fale com Ela.

O cinema almodovariano desestabiliza o conceito de ideal regulatório (FOUCAULT, 1988), que normatiza e controla os corpos dos indivíduos. Parte de suas obras evidencia o cotidiano de mulheres fortes, guerreiras, independentes e sexualmente resolvidas. Será em Fale com Ela, porém, que os dramas de homens frágeis, sensiveis e românticos constituirão o mote principal da trama.

A categoria do sexo sempre foi normativa (BUTLER, 2000). Os corpos dos indivíduos foram (e ainda são) constantemente controlados por regras que 
devem ser adotadas tanto por homens quanto por mulheres. Na obra, o diretor (des)constrói as relações de poder ao confrontar e contrastar personagens masculinas e femininas aproximando-as dos campos morfológicos e semânticos de ambos os gêneros.

Uma das personagens mais complexas da trama é Benigno. Em momento algum Almodóvar deixa claro qual a real orientação sexual do enfermeiro. Porém esta atitude do diretor é proposital. Para Louro (2000), as pessoas aprendem a classificar os sujeitos pela forma como elas se apresentam corporalmente. Sendo assim, os/as telespectadores/as questionam a sexualidade de Benigno pelos seus gestos e maneiras de se expressar. No hospital em que o enfermeiro trabalha todos / as acreditam que ele seja gay. Para seus / suas colegas de profissão, o fato de ele cuidar de Alicia, massageando-a, fazendo suas unhas e penteando seus cabelos atesta sua homossexualidade. Além disso, Benigno é um homem extremamente sensivel, característica que o aproxima do domínio das feminilidades.

A personagem em análise é vista como um ser estranho por romper as fronteiras dos gêneros. Os códigos culturais exigem do sujeito masculino um comportamento distinto do "sexo oposto", devendo exorcizar a feminilidade de dentro de si, para somente desta maneira conservar um status de virilidade. É a obediência às normas de virilidade que garante certos privilégios e autoriza o homem a frequentar determinados ambientes sociais. A construção da masculinidade ou seu fundamento é atravessado pelo temor do que é feminino. Porém, deve-se questionar até que ponto a aproximação com um determinado gênero pode definir a orientação sexual do indivíduo. Afinal, tendo cometido 0 estupro contra Alicia, pode Benigno ser considerado homossexual, na acepção geral do termo?

Como bem notara Gallina (2008), nos filmes de Almodóvar os gêneros nunca exercem um papel social definido, mas são construções ininterruptas cujos rumos dependerão da vivência de cada personagem. Homens e mulheres não são alguma coisa, mas vivem uma determinada condição, que pode mudar a qualquer momento. Lydia é apresentada como uma mulher de traços fortes e viris. Sua profissão de toureira é um verdadeiro desafio para sua posição: deve demonstrar a coragem que não se espera de uma legítima fêmea. O processo de masculinização é crucial para sua própria sobrevivência num espaço de predominância masculina. Tornar-se menos mulher talvez seja o único modo de defender-se do fatalismo a que está submetida pela marcação social de seu gênero.

Porém, se na arena, diante do público, Lydia é vista como uma mulher destemida, outra face de sua identidade se revela no seio privado. Ela é uma mulher que tem fobia a cobras. Sua fragilidade exacerbada apaga, por um momento, a lembrança da personagem forte anteriormente apresentada. Isso atina para a percepção de que o ser humano é puro devir e que há várias identidades convivendo num mesmo corpo, nem sempre harmoniosas, mas imperativas na formação de uma consciência e motivadoras de constantes mudanças. As categorias de gênero não fogem a essa regra.

Com o advento das teorias feministas e, posteriormente, dos estudos pós-estruturalistas e multiculturalistas, o fascismo que havia se instalado no domínio dos gêneros foi questionado. $\bigcirc$ alicerce das ideologias heteronormativas, responsável pela secção dos papéis sociais, a partir do aspecto funcionalista do corpo, sofreu paulatinos abalos a ponto de forçar a reestruturação do próprio sistema, numa tentativa desesperada de sobrevivência.

A masculinidade, até então intocada, pela primeira vez, passou a ser alvo de críticas e formulações teóricas diversas. Na prática, a abertura de novas perspectivas possibilitou aos homens pensarem e repensarem o lugar social que ocupam, e a duvidar da aparente naturalidade de comportamentos típicos dos homens, como o machismo e a misoginia. Entretanto, os avanços ainda podem ser considerados moderados.

O jornalista Marco Zuluaga, por exemplo, diverge do conceito de masculinidade ideal, que oprime os homens, negandoIhes o direito de externalizar seus sentimentos, impondo um sentido maior de força, agressividade e virilidade. Ele é um homem sensível, romântico e não hesita em demonstrar seus sentimentos ou admitir sua fraqueza diante dos acontecimentos. Marco representa um novo exercício de masculinidade, uma masculinidade que permite a expressão de alguns traços sentimentais, mas que ainda encontra impasse pelo imperativo da vigência dos códigos sociais. $O$ envolvi- 
mento emocional e afetivo que mantém com Benigno, em alguns momentos, pode causar a sensação de que a personagem vacila em sua orientação heterossexual, o que é apenas sugerido e intencionalmente evidenciado por Almodóvar.

É com a personagem Katerina Bilova que o diretor vai explicitar o quanto o imperativo da heteronorma ainda regula as relações sociais. Ela nutre um grande amor por sua pupila, Alicia. Entretanto, por ser professora de balé, cabe-Ihe conter os seus desejos, representando assim um ideal hegemônico que controla e impõe limites aos corpos e aos desejos. Katerina é assolada pelo "[...] fantasma normativo do sexo" (BUTLER, 2000, p. 112), que a obriga a manter padrões "higienizados"

de comportamento. Isso se torna nítido quando num rápido diálogo que a professora tem com Marco, ao final do filme, sentencia: "Nada é simples (grande pausa) sou professora de balé e nada é simples".

Sua fala está atravessada de silêncios, de estratégias que ora ocultam e ora deixam escapar seus sentimentos, diferentes maneiras de dizer (ou não) o que sente e de exteriorizar sua "admiração" por Alicia. Esse mecanismo funciona como um determinante das condutas consideradas razoáveis ou absurdas não somente desta, mas de todas as outras personagens, eivadas que estão pela possibilidade de cisão e concorrente adequação às normas sociais estabelecidas, fragmentando-as em suas subjetividades e subsequentes representações sexuais.

"FALE COMIGO": ALGUMAS CONSIDERAÇÕES FINAIS
Fale com Ela é um filme sobre mulheres protagonizado por homens. A morbidez dos corpos femininos em contraste com a ação masculina encerra uma hipótese metonímica: o imperativo sexual é um jogo cujas regras de permanência e mudança depende de influências multilaterais, discursos de poder e atos de transgressão sem uma conexão aparente. Os deslocamentos ou desvios das personagens na trama nos faz questionar até onde pode o amor ser um elemento transformador e até em que ponto se torna uma obsessão perigosa, mortal.

Nesse sentido, Almodóvar, em Amante Minguante, nos conduz a um laboratório em que uma cientista está a fazer novos experimentos com substâncias para fins estéticos. Embora destinado ao público feminino, quem experimenta a nova fórmula é seu marido. A preocupação feminina da estética é apropriada pelo homem. Esta apropriação resulta numa diminuição do masculino em relação ao feminino, representada pelo encolhimento do amante. $O$ final resulta no desaparecimento do macho dentro da fêmea, pela entrada completa do homem na mulher.

O curta permite duas leituras: a consumação do amor é a morte implicando o renascimento desse amor numa forma genuína, o surgimento do sentimento entre Marco e Alicia, e a desestabilização das noções de gênero e de subversão da lógica binária dos sexos. Almodóvar, afinal, não se cansa de transgredir as normas, ao arriscar e debater novas e delicadas perspectivas sobre o universo da sexualidade (SILVA ROCHA \& PEREIRA SANTOS, 2014).

\section{REFERENNCIAS:}

ALMODÓVAR, Pedro. A lei do desejo [Ley Del deseo, La] Espanha, 102 min. DVD 1987.

\section{De salto alto}

[Tacones Lejanos] Espanha, 112 min. DVD 1991

Fale com ela

[Hable Com Ella] Espanha, 112 min. DVD 2002.

A pele que

habito [La Piel Que Habito] Espanha, 120 minutos. DVD 2011.

AMATUZZI, Mauro Martins. Experiência: um termo chave para a psicologia. Memorandum 13, Belo Horizonte, nov./2007, p. 08-15. Disponivel em:

<http://www.fafich.ufmg.br/ me mo

randum/a13/01Amatuzzi.pdf> Acesso em: 19 de maio de 2019.

BARBALHO, Aparecida Mendes Os (des)compassos do amor na Quadrilha de Drummond. Cefapro Cáceres. 2009.

Disponivel em

<http://www.cefaprocaceres.co m.br/index.php?

option=com_content\&view=artic le\&id=826:os-des-compassos do-amor-naqua drilhadedrummm ond\&ca tid=28:artigo\&ltemid=77> Acesso em: 21 de maio de 2019.

BAUMAN, Zygmunt. Amor líquido. Tradução de Carlos Alberto Medeiros. Rio de Janeiro: Zahar, 2004.

BUTLER, Judith. Corpos que pensam: sobre os limites discursivos do sexo. Trad. de Tomaz Tadeu da Silva. In. LOURO, G. L. (Org.). O corpo educado. 2. ed. Autêntica: Belo Horizonte, 2000. p. 110-125. 
FOUCAULT, MICHEL. VIGIARE PUNIR: NASCIMENTO DA PRISÃO. TRADUCÃ̃ DE RAQUEL RAMALHETE. PETRÓPOLIS: VOZES, 1987.

História da sexualidade I: a vontade de saber. Tradução de Maria Thereza da Costa Albuquerque e J. A. Guilhon Albuquerque. Rio de Janeiro, Edições Graal, 1988.

GALLINA, J. F. Instigando o olhar: as identificações queers nos filmes de Pedro Almodóvar (1999-2004). 2008. Dissertacão (Mestrado em História) Programa de Pós-Graduação em História, Universidade Federal de Santa Catarina, Florianópolis.

Micropolíticas

almodovarianas:

performatividade de gênero no cinema espanhol. Revista Ártemis, vol. 11, dez. 2010, p. 87101. Disponivel em:

<http://132.248.9.34/hevila/Revi staArtemis/2010/vo/11/7.pdf>. Acesso em: 16 de mai de 2019.

LAGO, G. de C. P. Conectividade: um estudo sobre o amor pós-

moderno. 2009. $88 \mathrm{f}$.

Dissertação (Mestrado em

Psicologia). Instituto de

Psicologia, Pontificia

Universidade Católica de Minas

Gerais, Belo Horizonte. 2009.

LOURO, Guacira Lopes. Cinema e sexualidade. Revista Educação e Realidade, v.33, n.7, p. 81-98, Jan/jun 2008. Disponivel em <http://seer.ufrgs.br/index.php/ educacaoerealidade/article/view /6688/4001>. Acesso em: 18 de mai. de 2019.

\section{Pedagogias da}

Sexualidade. In: LOURO, G. L.

(Org.). O corpo educado. 2. ed.

Autêntica: Belo Horizonte, 2000.

p. 04-24.

Acesso em: 05 de junho de 2019.
PLATÃO. O BANQUETE. TRAD. JOSÉ CAVALCANTE DE SOUZA. 5. ED. SÃO PAULO: NOVA CULTURAL, 1991. COLECÃO OS PENSADORES.

RIBEIRO, João Ubaldo. A Casa dos budas ditosos. Rio de Janeiro: Editora Objetiva, 1999. (Série Plenos Pecados, 4ำ vol.).

\section{RODRIGUES, C.; HEILBORN, M.}

L. Construindo Vera Cruz e desconstruindo o gênero: aproximações entre Pedro Almodóvar e Judith Butler. Sexualidad, Salud y Sociedad Revista Latinoamericana, n. 16, abr. 2014, pp. 73-85. Disponivel em: <http://www.sexuali dadsaludysociedad.org/>. Acesso em: 18 de mai. de 2019.

SCOTT, Joan. Gênero: uma categoria útil para análise histórica. Tradução: Christiane Rufino Dabat e Maria Betânia Ávila. Revista Educação e Realidade, v. 20, n. 2, p. 71-99. Jul/dez 1995. Disponivel em. <https://seer.ufrgs.br/educacao erealidade/article/view/71721/40 667>. Acesso em: 29 de agosto de 2019

SILVA ROCHA, Caio César. PEREIRA SANTOS, Danilo.

Estranhos Familiares: a inserção das personagens

homo/lesbo/bi/transexuais no cinema. Revista Periódicus, v.1, n. 1. mai/out 2014, p. 206-221.

Disponivel em

<http://www.portalseer.ufba.br/i ndex.php/revistaperiodicus /article/view/101 72/7261>.

Acesso em: 20 de mai. de 2019 . ROCHA JUNIOR,

Alberto Ferreira da. Quem tem medo das "bee"? teatro e diversidade sexual na educação básica. In: História, política e cena: tecnologia e cena política (cadernos monográficos - vol. II). Anais...São João del Rei(MG) UFSJ, 2019. Disponivel em: <https//www.even3.com.br/anai S/IISHPC_UFSJ_2018/124894QUEM-TEM-MEDO-DAS-BEETEATRO-E-DIVERSIDADESEXUAL-NA-EDUCACAOBASICA>. Acesso em: 05 de junho de 2019.

VIESENTEINER, Jorge Luiz. O conceito de vivência (erlebnis) em Nietzsche: gênese,

significado e recepção. KRITERION, Belo Horizonte, no 127, Jun./2013, p. 141-155.

Disponivel em: <

http://www.scielo.br/pdf/kr/v54 n127/n127a08.pdf>. Acesso: 19 de maio de 2019.

1 - Erlebnis apresenta triplice significação: "a) a imediatez (Unmittelbarkeit) entre homem e mundo; b) a significabilidade (Bedeutsamkeit) para o caráter global da existência; e c) a incomensurabilidade (Inkommensurabilität) do conteúdo da própria vivência, conferindo a ela também uma dimensão estética". também uma dimensão estética".
(VIESENTEINER, 2014, p. 141, grifos do autor). Possui estreita ligação com pathos.

2 - Energia psíquica que se origina no corpo e alcanca a mente (mental e somático), gerando uma tensão que exige ser descarregada. Freud distingue dois tipos de pulsões básicas: a pulsão da vida ou sexual, personificada em Eros, e a pulsão da morte ou agressiva, personificada em Tanatos.

3 - Palavra derivada do termo grego phatos. Conceito caro à filosofia Nietzsche, usado primeiramente por Descartes, designa travessia ou vivência completa, sentida profundamente no curso do acontecimento. Desse modo, está ligado ao sofrimento, padecimento de algo vivido, podendo ser suportado corporal e espiritualmente. Possui estreita associação com o termo Erlebnis.

4 - O mesmo que Cupido, na mitologia grega. Filho de Afrodite, que irritada pela fama da beleza de Psiquê, incumbe-Ihe de castiga-la ao fazer apaixonar-se por um ser desprezivel. Ao encontra-la dormindo. Cupido fica tão extasiado diante de sua formosura que acidentalmente fere-se com a própria seta e se apaixona por ela.

5 - A personificação da morte, na mitologia grega. Na mitologia romana, equivale a Mors ou Leto.

6 - Segunda instância do psiquismo freudiano responsável pela estruturação do eu pelo princípio da realidade objetiva. "[...] O eu faz eco às demandas do isso e seus impulsos, mas sua função consiste em satisfazê-los ou não, segundo as possibilidades oferecidas pela realidade, suspendendo a busca por prazer, sob pena de entrar em conflito com a mesma". (LAGO, 2009, p. 41) 
6 - Terceira e última instância do psiquismo freudiano responsável pela oposição radical aos desejos do isso (ou id). O superego aproxima-se do conceito de civilização ao incorporar as normas e os valores sociais desenvolvidos no cerne de cada sociedade. "[...] Pode-se dizer que é a sociedade internalizada no próprio indivíduo, com suas leis e regras, muitas vezes fonte de inibição para o eu". (idem, ibidem).

Recebido em 01 nov 20190 | Aprovado em 29 nov 2019

\section{Danilo Pereira SANTOS}

Mestre pelo Programa de Mestrado Profissional em Letras da Universidade Estadual do Sudoeste da Bahia (UESB). Graduado em Letras Vernáculas pela mesma instituição. Professor de Língua Portuguesa da Rede Municipal de Ensino de Jequié (BA).E-mail: danpereirasan@gmail.com

\section{Caio César Silva ROCHA}

Mestrando pelo Programa de Pós-Graduação em Artes Cênicas da Universidade Federal de São João delRei (UFSJ). Especialista em Metodologia do Ensino de Arte pela UNINTER. Graduado em Licenciatura em Teatro pela Universidade Estadual do Sudoeste da Bahia (UESB). Pesquisador voluntário no grupo:

"Diversidade sexual e teatro no Brasil: visibilidade, minoritarismo e representação" (UFSJ). Ator. Professor de Arte da Rede Estadual de ensino da Bahia.

E-mail: caioroitman@gmail.com 